\title{
EMPLOYING INTERPRETIVE RESEARCH TO BUILD THEORY OF INFORMATION SYSTEMS PRACTICE
}

\author{
Bruce Rowlands \\ School of Computing \& Information Technology \\ Griffith University, Nathan, Australia \\ B.Rowlands@Griffith.edu.au
}

\begin{abstract}
This paper provides guidance and an example for carrying out research using an interpretive framework. Until quite recently, there has been little available in the IS literature to guide the interpretive researcher to build theory of IS practice. While structured as a typical research paper, this paper is different in that the focus is on conceptual issues and the research methods rather than the findings. Unlike positivist research, there is no accepted general model for communicating interpretive research. Similarly, few guidelines exist for conducting the inductive process central to interpretive research. Throughout the paper, issues relating to the choice and application of the methods in terms of conducting inductive research are discussed. Overall, the focus provides an in-depth discussion of the particular interpretive research that I undertook so that other researchers can read of an example that may be similar to their own and therefore guide their work.
\end{abstract}

Keywords: IS research methodologies, interpretive perspective, case study, grounded theorising.

\section{INTRODUCTION}

This paper provides guidance and an example for carrying out research using an interpretive framework to build theory of IS practice. The paper provides an example of (a) developing a theoretical framework, (b) how to choose an appropriate research method, (c) particulars of data collection and analysis, and (d) appropriate evaluative criteria applicable to interpretive research. The research example is a large-scale doctoral study of decision-making by owner-managers of small firms in the IT industry. The aim of the study (1) was directed toward exploring and describing the decision making process of owner/managers regarding their participation with on-the-job training schemes for the first time; and (2) to develop process theory explaining their participation. While structured as a typical research paper, this paper is different in that the focus is on describing the research process, conceptual issues and the research methods used rather than the findings. This format is important for two reasons: (1) unlike positivist research, there is no accepted general model for communicating interpretive research. (2) Similarly, few guidelines exist for conducting the inductive process central to interpretive research. Throughout the paper, issues relating to the choice and application of the methods in terms of conducting inductive research are discussed. Given both the practical importance of, and scarcity of, interpretive research in information systems I feel that documenting the decisions about the research process may be particularly valuable to researchers in the information systems community.

\section{THE NATURE OF INTERPRETIVE RESEARCH}

It is important first of all to define what I mean by interpretive research and to draw a distinction between a related term - qualitative research. Firstly, the term interpretive is not a synonym for qualitative. Qualitative research can be interpretive or positive depending on the philosophical assumptions of the researcher (Cavaye, 1996). According to Van Maanen (1979), qualitative research is an umbrella term covering an array of techniques which seek to describe, decode, translate, and somehow come to terms with the meaning, rather than the measurement or frequency of phenomena in the social world. In other-words, qualitative research tends to work with text rather than numbers. Interpretive research, on-the-other-hand, is a more specific term and is defined in terms of epistemology.

Following Klein \& Myers (1999), the foundation assumption for interpretive research is that knowledge is gained, or at least filtered, through social constructions such as language, consciousness, and shared meanings. In addition to the emphasis on the socially constructed nature of reality, interpretive research acknowledges the intimate relationship between the researcher and what is being explored, and the situational constraints shaping this process. In terms of methodology, interpretive research does not predefine dependent or independent variables, does not set out to test hypotheses, but aims to produce an understanding of the social context of the phenomenon and the process whereby the phenomenon influences and is influenced by the social context (Walsham, 1995). In terms of phenomenological approach, in interpretive research theory is generated or induced from the data collected, thus it is grounded in the data. In comparison, theory is deduced by testing hypotheses in positivist research. 


\section{SCOPE \& ORGANISATION OF THIS PAPER}

Keeping the above definition of interpretive research in mind, the scope of this paper is to clarify (by way of example) the nature of interpretive research methods, and to advise others how to employ interpretive methods. In reference to Klein \& Myers' (2001) classification scheme for interpretive research in IS, this paper can be identified and characterised as advancing interpretive research methods. Before embarking on a research project a researcher needs to define how he/she is conducting the research, what theoretical lens is being applied, and what methods are most appropriate to collect and analyse the data. We look at these issues and then illustrate how they were applied in the particular research example.

The paper is organised as follows. The first section lays the foundation by considering important factors that influence the choice of qualitative methods, and in particular, an interpretive approach for IS research. The section following is applied and focuses on building a theoretical framework, and conducting interpretive process-oriented research, respectively. Subsequent sections describe the particulars of data collection and analysis and associated evaluative criteria once the research method was chosen. The last section discusses implications of the methods employed and some issues faced when conducting this kind of research.

\section{FACTORS INFLUENCING THE CHOICE OF QUALITATIVE METHODS}

Trauth (2001) lists five factors influencing the choice of qualitative methods in IS research. The first factor is the nature of the research problem, second is the researcher's theoretical lens, and the third is the degree of uncertainty surrounding the phenomenon. These three main factors are now illustrated by way of example in the ensuing sections.

\section{THE RESEARCH PROBLEM}

Trauth argues that the nature of the research problem should be the most significant influence on the choice of a research methodology. "That is, what one wants to learn determines how one should go about learning it" (Trauth, 2001: 4). I go further and state that what we want to learn will help shape the research questions posed, and the questions posed will depend on the stage of knowledge accrual about the phenomenon. These two factors may be distinct but in my view they are nevertheless interrelated.

Based on research documented in Rowlands (2001), this section provides a narrative of how I came to commence the research, how I initially identified the research problem, and how the subsequent research questions were posed. The impetus began in 1995. For a number of years prior to the conduct of this study, I was a manager within a large training provider in New South Wales, Australia. Toward the end of 1995, I was approached by an Information Technology Industry Training Advisory Board to manage a pilot program involving the introduction of an Australian Qualification Framework level-4 traineeship in Information Technology. This program provided employees with a recognised qualification and competencies in networking, communications equipment, and PC hardware implementation.

As part of this pilot program, I was responsible for securing the participation of industry, and managing the delivery of the off-the-job training. It was then, from a training provider's perspective, that the vexing problem of a lack of employer participation became evident. One question that kept recurring in my mind was, given that there was (and still is) considerable demand by industry for the skills and competencies supplied by the program, and a large pool of suitable trainees to recruit from, why weren't small and medium sized enterprises participating? Eventually, this experience led to the commencement of this study, the framing of the problem, and to the later definition of the research questions.

As a manager responsible for providing IT training, I wanted to research this problem and hopefully contribute some of the findings back into practice. As a starting point I turned to the literature for possible answers. A review of the literature told me that there had been a number of studies undertaken and reports published providing solid data identifying key constructs and variables relating to training in small business in general. For instance, enough was known about the following kinds of questions: What is the general attitude of small business to current training reforms? What factors and contextual elements influence the decision of small firms to participate? What is the current level of knowledge in small business about formal workplace training procedures? These predominantly 'what' type questions indicated to me that only one half of the problem had been examined. For instance, we did not know enough about why some firms decided to participate, of those that did, how they arrived at their decision. In other-words, using Trauth's phrase 'what I wanted to learn' was expressed as: I wanted to know the processes small firms in the IT industry went through in making their decision.. 
I identified a need for a research method enabling me to explore and then provide an explanation to this problem - which involved the 'how one should go about learning it'. From knowledge obtained in graduate courses on research methods, I chose the in-depth case study because my desire was to uncover the "story behind the factors" about the reluctance of small employers to participate with formal on-the-job training schemes. The case study has been an essential form of research in the social sciences, and has been used in research involving small business (Chetty, 1996), and extensive research within organisations (Cavaye, 1996). According to Yin (1994), a major strength of the case study is that it allows the researcher to understand the problem, the nature and complexity of the process taking place; and valuable insights can be gained into new topics emerging in the rapidly changing field, such as training practices in the IT industry. In addition, case research can contribute to knowledge by relating findings of the particular to generalisable theory.

After this initial review of the literature, I was firming in my mind that the research approach most appropriate to the problem would be exploratory, most likely inductive, and as discussed later, would be a process study. At this early stage I hadn't chosen a method of data analysis, but I knew of grounded theory and I do admit to having a personal preference for qualitative research over quantitative approaches. To recap at this stage, what one wants to learn - the subtleties of the decision-making process — determines how one should go about learning it - the case method. The next section discusses the second of Trauth's factors - theoretical lens when choosing qualitative, interpretive methods.

\section{THE RESEARCHER'S THEORETICAL LENS}

Trauth's (2001) second important influence on the choice of research method is the theoretical lens that is used to frame the investigation. By theoretical lens, Trauth is referring to philosophical issues of epistemology and a choice among positive, interpretive and critical studies. For researchers, the starting point is to identify our philosophical and theoretical assumptions leading us to choose an appropriate methodology. The following paragraphs make explicit my fundamental assumptions about the nature of knowledge (epistemology), and the nature of ways of studying phenomena (methodology).

Like all fields of inquiry, organisational study is paradigmatically anchored. An interpretive paradigm is based on the view that people socially and symbolically construct their own organisational realities (Berger \& Luckman, 1967). By adopting an interpretive approach, I also assume that the participation decision-making process and the perceived meaning of on-the-job training schemes are not objective phenomena with known properties or dimensions. The research approach, accordingly, is consistent and compatible with the epistemological and ontological assumptions that the world and reality are interpreted by people in the context of historical and social practices. That is, experience of the world is subjective and best understood in terms of individuals' subjective meanings rather than the researcher's objective definitions. By choosing the assumption of subjectivity and interpretivist methods for research, this example claims that the aspects of the phenomena under investigation - the participation process - are too complex to define and measure with standard instruments. In order to gain greater knowledge about owner managers' willingness to participate with on-thejob training schemes, the example proposes a method capable of capturing social meanings of participation, as generated by owner/managers of small firms. The proposed method is the interpretive case study.

Researchers working with the case method can employ either a positivist or interpretivist approach, or a combination of both, irrespective of whether the intent is to test or develop theory (Markus, 1994; Cavaye, 1996). However, interpretivism and positivism rely on quite different assumptions about the nature of knowledge and demand different approaches to research.

Positivism for instance, assumes training initiatives to be an objective, external force that have relatively deterministic impacts on organisations. The researcher is seen to play a passive, neutral role in the investigation, and does not intervene in the phenomenon of interest. Positivist studies are premised on the existence of a priori fixed relationships within phenomena, typically investigated with structured instrumentation. Such studies serve primarily to test theory, in an attempt to increase predictive understanding of phenomena. Positivist studies are characterised by the inclusion of formal propositions, quantifiable measures of variables, hypothesis testing, and the drawing of inferences about a phenomenon from the sample to a stated population.

In contrast, an interpretive study - such as this research - focuses on the human action aspect of training initiatives, seeing participation as a product of interpretations, interventions and individual decisions. Interpretive researchers thus attempt to understand phenomena through accessing the meanings that participants assign to them. In direct contrast to the positivist studies, interpretive researchers reject the possibility of an 'objective' or 'factual' account of events and situations, seeking instead a relativistic, albeit shared (between the researcher and the interviewee) understanding of phenomena. Generalisations from the setting, usually from a small number of case studies, to a population is not sought; rather, the intent is to understand the deeper structure of a phenomenon, which it is believed can then be used to inform other settings. For a more detailed account of the positivist and interpretivist research philosophy, see Orlikowski 
and Baroudi (1991), Lee (1991), Klein and Myers (1999) or the MIS Quarterly Website at http://www.qual.auckland.ac.nz/ and click on 'philosophical issues'.

Because of the importance attached to understanding decision-making from the perspective of owner/managers and the absence of specific prior research describing the processes involved in training initiatives participation; the research approach used was both interpretive and primarily inductive. According to Lincoln \& Guba (1985) the use of an inductive approach is appropriate when studying organisational phenomena from a primarily interpretive perspective. This perspective regards humans as active agents and their behaviour as generally indeterminate. Unlike physical stimuli, the training initiative scheme may produce novel interpretations by owner/managers as they are applied in this particular social context.

In summary, the emphasis in this research example was on interpreting how owner/managers understand their situation, their attitudes towards training initiatives and their relationships with training providers. The researcher's theoretical lens - involving both perspective and method - is in the realm of interpretive and qualitative research.

Trauth's third factor, the amount of uncertainty surrounding the phenomenon under study, is discussed next.

\section{DEGREE OF UNCERTAINTY SURROUNDING THE PROBLEM}

While I had made clear my own epistemological preference in the previous section, certain contingencies of the problem — such as degree of uncertainty surrounding the topic — also confirmed my qualitative, inductive, interpretive stance. For example there was little prior research investigating the conditions under which small businesses were prepared to engage in formal training schemes, or the issues involved in their decision-making process. Of the research that had been undertaken, the dominant paradigm (or theoretical lens) had been positivist with an emphasis on factor analytic studies and surveys as the main methods of analysis and data collection. The preliminary review of the literature identified previous research to be overreliant upon mail surveys and telephone interviews with factor analysis as the main data analysis technique. The positivist lens told us that various factors were influential — "the what", but it could not tell us "why" managers participated as they did. It could not provide us with an in-depth look at the worldviews that sat behind the facts shared by the owner-managers. There was very little attention given to the intentions, actions, context or processes surrounding participation that explained how these issues interact and how and why participation outcomes were associated.

In light of the paucity of previous research on the process of participation, the research example provided an alternative perspective to an emerging research topic. I argued that without more emphasis on the dynamic nature of the participation process, an incomplete understanding of the uptake problem would result. I argued further that more attention should be paid to the development of new theory more fully specified through grounded research that are better able to account for the phenomenon under investigation. In pursuit of these dual objectives, the outcome focus of this study was aimed at theory building, not theory testing, for the purpose of describing and explaining the participation process. In sum, the degree of uncertainty surrounding the problem - limitations in the literature and the nature of the problem - influenced me to choose an inductive approach and grounded theory techniques for data analysis. Grounded theory will be explained in the Research Procedures section.

To conclude this section, I have reviewed and applied three main factors as espoused by Trauth (2001) influencing the choice of qualitative methods for IS research. The three factors are: the nature of the research problem, the researcher's theoretical lens, and thirdly, the degree of uncertainty surrounding the problem. I also introduced the interpretive case study as a method for seeking a shared (between the researcher and the interviewee) understanding of phenomena.

Before ending this section it needs to be acknowledged that Trauth (2001) identified two additional factors that influence the choice of qualitative methods for IS research. The $4^{\text {th }}$ factor is the researcher's skills. I have already alluded to my preference based on prior research training to using qualitative methods. The $5^{\text {th }}$ factor academic politics, was not an issue as the research centre I was working in expressed no preference involving the choice of positive, interpretive or critical methods. However, each researcher's circumstances are different and these two additional factors may well prove to be relevant when choosing an 'appropriate method' for IS research.

Further issues that accompany these influences are at the core of this paper. The following section focuses on three further practical issues that were involved in the conduct of the empirical research. These issues involved (1) how I conceptualised the problem, (2) an emphasis on process oriented research, and (3) building a theoretical framework, respectively. 


\section{PRACTICAL ISSUES RELATED TO DEVELOPING A THEORETICAL FRAMEWORK}

\section{CONCEPTUALISING THE PROBLEM}

Given my epistemological stance, I rationalised that an interpretive analysis of the texts were needed to get at the why of the participation decision-making behaviour and the mechanics of the how within the particular context. However, this was not sufficient in itself to commence the theory building process. As part of this process, I asked myself as a researcher, how could I improve our research models, and also our methodologies and perspectives so that the results of my work would be of greater value to policy-makers and practitioners. To provide an alternate perspective to this under-researched topic, I conceptualised the problem of training participation as a process of socio-technical innovation. In undertaking this research, I qualified this judgement by reviewing and discussing definitions of innovations, technology, social technologies and argued a case for understanding on-the-job training schemes as an innovation in the process of acquiring skills within the firm. For example, I borrowed from Perrow (1967) who sees organisations as places where raw materials are transformed, thus defining what is done and how it is done - the process - as the technology of organisations. This perspective of viewing on-the-job training as a process of socio-technical innovation departs from the bulk of the literature (Saunders, 2001) that shared a conventional economic focus on how firms make decisions about skilling. Alternatively, by focusing on the problem as a process of socio-technical innovation, I began to develop a theoretical framework comprised of individual, organisational, social, governmental and economic forces that introduced some typically unexamined aspects of participation within small firms.

In building this framework, the thesis discussed theory that addressed the concepts of innovation and social technologies. One theory - the social construction of technology (Bijker et al, 1987) - describes a theoretical approach to studying the meanings of technology, and how those meanings affect the adoption of technology within an organisation. A second theory - innovation diffusion theory (Rogers, 1995) provided a general explanation for the way new ideas and objects spread through a social system over time. These literatures and a framework of process-oriented research (to be discussed next) provided valuable tools for the examination and analysis of the participation decision-making process.

\section{AN EMPHASIS ON PROCESS ORIENTED RESEARCH}

The second major conceptualisation that departed from the bulk of previous research involved a focus on process. I advocated a need for process-oriented research based on Mohr's (1982) classification. Mohr (1982) suggests that two fundamentally different types of theoretical approaches can be used to investigate organisational phenomena: variance and process research. The majority of prior research (Smith, 1995; Hayton, 1996) was of the variance persuasion with a focus on correlations between groups of variables and a specific outcome, while my approach involving process research aimed to understand the sequence of events leading to some result over time.

To understand more about process-oriented research Wolfe (1994) differentiates two generations of process research. Earlier work, called stage model research, conceptualised innovation as a series of stages that unfolded over time. The purpose of this early work was to determine whether the innovation process involved identifiable stages, and, if so, what they are and in what order. The second generation of process research involves in-depth, longitudinal, research conducted to fully describe the sequences of, and the conditions which determine, innovation processes. This type of research often involves theory building and qualitative data collection. Examples of process research that I reviewed following this research stream included: Eisenhardt (1989a), Wolfe (1994), Langley \& Truax (1994), Markus (1994), and Orlikowski (1996). These studies tend to be inductive, in-depth, examinations of how innovations develop over time. Methods employed include historical analysis of archival data and published reports, interviews, questionnaires, and field observations. The form of process modelling adopted in my research example is that of Second Generation Process Theory, where the objective is to provide a better understanding of how and why the "pieces of the puzzle" interact and work together to produce a participation decision.

\section{BUILDING A THEORETICAL FRAMEWORK}

The last practical issue relates to building a theoretical framework. A theoretical framework consists of a selection of concepts and relations among them, grouped so as to enable its users to easily see their structure (Whetten, 1989). To borrow again from Whetten, a theoretical framework can be understood by considering four building blocks, or four essential elements. Each element is described briefly in the following paragraphs. 
The first building block of a theoretical framework, "the what", refers to the elements (variables, constructs, concepts) that should be considered as part of the explanation of the phenomenon. As reported from an initial review of the literature, some conceptual and empirical research had provided researchers with a preliminary list of factors believed to be critical to participation.

However, the main contributions of this research were situated within the second building block of theory development, to determine conceptually "How" and "Why" the elements relate to each other. Having already argued that participation cannot be adequately explained by considering or manipulating one or two factors (the positive, dominant economic perspective), I mounted a case for a new perspective based on the concepts of socio-technical innovation, decision-making and process.

The third building block refers to a theory's assumptions - that is, the theoretical glue that welds the model together. Answers to the "Why" component push back the boundaries of our knowledge by providing compelling and logical justifications for altered views. "Only when a researcher can specify his (sic) logic, then he can follow certain rules in determining the propositions he can make about his theory" (Whetten, 1989). In a previous part of this section I discuss the use of $2^{\text {nd }}$ Generation Process Theory (Wolfe, 1994) as a meta-theoretical framework for studying the participation decision-making process. This meta-theory was used as part of my conceptual lens for describing and understanding the participation decision-making process. The last building block places limitations on the propositions generated from the theoretical model. Specifically, the "Who", "Where", "When" elements set the boundaries of generalisability, and as such establish the range of theory (Whetten, 1989). In this example, the research attempted to go beyond previous research by developing an initial set of theoretical propositions (sharpened by recourse to the full literature) regarding the dynamic nature of training initiatives participation in the IT industry in SE Queensland, Australia.

\section{INDUCTIVE VERSUS DEDUCTIVE RESEARCH}

In applying these 'four building blocks', in the development of my theoretical framework, I had to make a major decision of approach. For example, most qualitative researchers attempt to avoid prior commitment to theoretical constructs before gathering any data (Yin, 1994). Yet, as discussed by Whetten (1989), two different approaches may be taken, or combined. In the first, the researcher works within an explicit theoretical framework. Therefore, a theoretical framework becomes a researcher's first cut at making some explicit theoretical statements (Miles \& Huberman, 1994). This approach is known as deduction. In the second, the researcher tries not to be constrained by prior theory and instead sees the development of relevant theory, propositions, and concepts as a purpose of the project. This approach is generally known as induction. In my research example, both approaches were combined since the main intent was to study a relatively unresearched topic (the participation decision-making process involving small businesses and training initiatives in the IT industry) from a different perspective (training initiatives being defined as socio-technical innovations) within the bounds of an already well-established research program (technology adoption).

Yes, it is possible to be inductive, but I chose not to ignore previous work in the field. I developed a loose conceptual model built on over ten years of research that was a conceptual advance on the literature, especially Australian work. The model of the participation context within which small IT firms operated was, I proposed, comprised of at least six sets of issues: (1) the impact of the external environment such as the economy and government; (2) small business and adopter industry characteristics; (3) owner-managers attitudes (individual); (4) characteristics of the innovation (the training scheme) itself; and (5) supplier factors, such as the impact of training agencies/sponsors and training providers. These issues were also used to develop the initial coding scheme for the qualitative analysis of data (to be discussed in the Research Procedures section). (6) The sixth, and pivotal component of the model, the participation decision process, was developed and presented in The Findings section of the thesis, but does not form part of this paper's discussion. However, and this is a most important point, given that this study was aimed at theory building, not theory testing, the theoretical framework and model was used solely as a guide. It helped make sense of what occurred in the field, ensured that important issues were not overlooked, provided a set of tentative constructs to be investigated, and guided my interpretation and focus.

To summarise at this point, this section introduced the notion of a theoretical framework and Second Generation Process Theory to frame the empirical work. Second Generation Process Theory provided some methodological guidelines and a meta theoretical framework for understanding process, participation and innovation, from the perspective of owner managers. It also offered a perspective from which I could look at multiple local meanings of participation and proceed to understand how these meanings become crystallised and subsequently influence individual and organisational-level action. This use of the theory accords with Klein \& Myers' (2001) recommendation that the empirical research needs to be guided by (or at least informed by) one or more social theories. 
Having developed a theoretical framework and a conceptualisation of the problem as a process of sociotechnical innovation, I was then in a position to pose the specific research questions and to specify the research procedures in more detail. In the next section, the paper states the research questions and discusses a number of methodological issues associated with conducting the inductive process so central to interpretive research.

\section{METHODOLOGICAL ISSUES}

This section firstly justifies the use of grounded theory (Glaser \& Strauss, 1967) when conducting process oriented research and describes a number of distinguishing features that characterise this approach - inductive, contextual, and processual - that fit with the primarily interpretive rather than positivist orientation of this research. Next, the overall research design involving phases adapted from key exponents of the case method are detailed. A model depicting three main phases of inductive theory building using multiple cases presented in Figure 1. The section concludes with a discussion of credibility and reliability issues as part of the research design. The primary objective of this evaluative component was to manage potential threats to the validity of the results given the 'subjective' nature of data collection.

\section{REASONS FOR USING GROUNDED THEORY TECHNIQUES}

I chose grounded theory (GT) techniques to analyse my case study interview data because, according to Strauss \& Corbin (1990), grounded theorising is well suited to capturing the interpretive experiences of owner/managers and developing theoretical propositions from them. In the same line of thought, an application of GT is appropriate when the research focus is explanatory, contextual, and process oriented (Eisenhardt, 1989b). Similarly, GT has been effectively used in recent IS research (Jones \& Hughes, 2001; Galal 2001; Urquhart, 2001) to develop theory of IS practice. The Research Procedures section provides more details of the 'how to' of coding and grounded theorising, while readers are encouraged to consult Urquhart (1997) and Urquhart (2001) for specifics of some practical and philosophical issues associated with its application.

In brief, the methodology of grounded theory is iterative, requiring a steady movement between concept and data, as well as comparative, requiring a constant comparison across types of evidence to control the conceptual level and scope of the emerging theory. To facilitate this iteration and comparison, eight field sites were studied, with the research design expanded upon in the next section.

\section{THE RESEARCH DESIGN}

The research design for theory building is illustrated in detail in Figure 1. Figure 1 is an adaptation from Yin (1994) and follows Eisenhardt's (1989b) replication approach to multiple case studies. 
Figure 1

The specific research plan, adapted from Yin (1994) \& Eisenhardt (1989b)

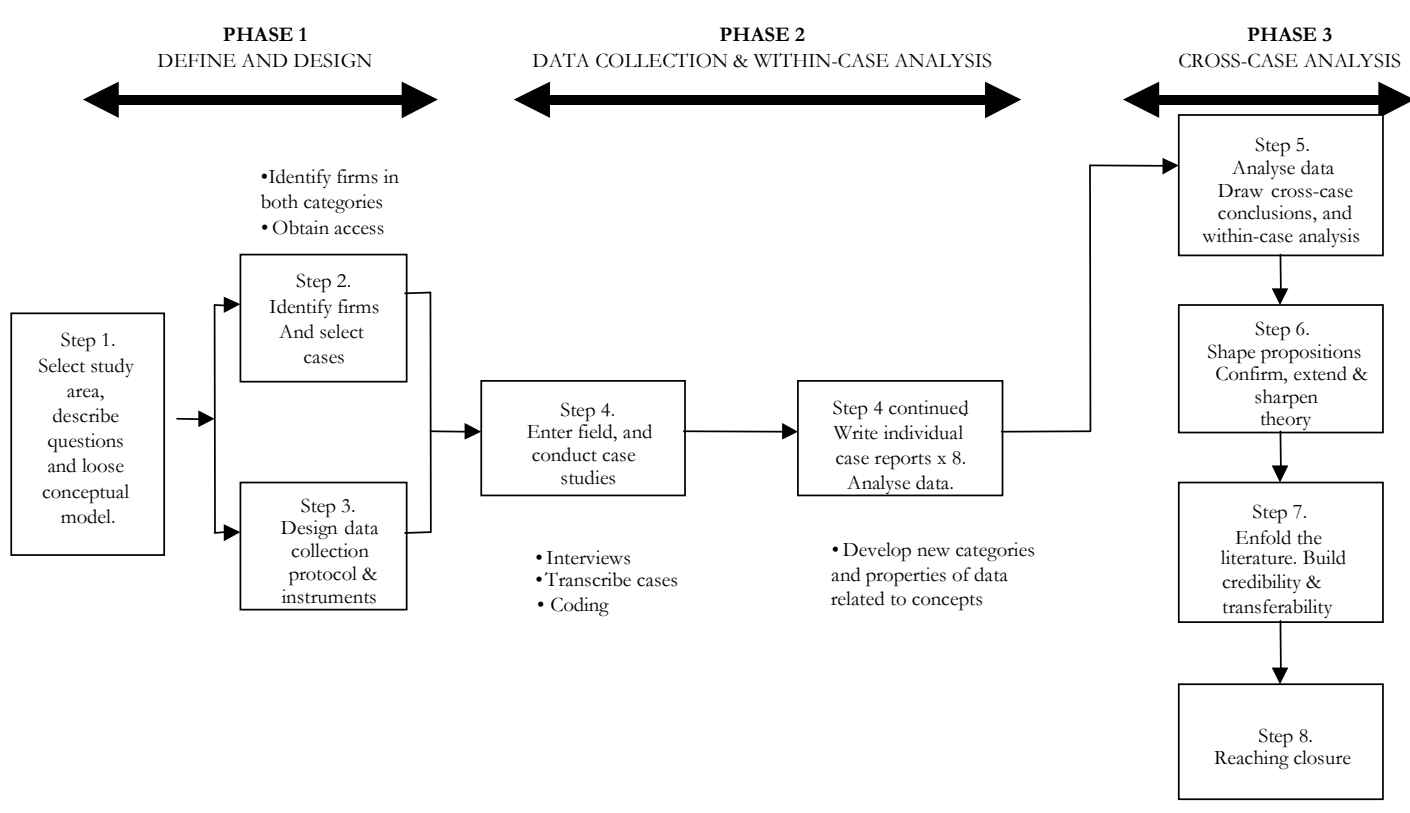

The first step involved stating the research questions and defining a preliminary conceptual model that initially, told me where to look for relevant evidence. The role of loosely specifying a conceptual model prior to the conduct of any data collection is a major point of difference between the research adopted compared to a purely inductive approach. In fact, I chose this approach essentially because it provided a more "tighter" design, in keeping with the following contingencies.

Firstly, I had a good prior acquaintance with the research problem; I knew something conceptually about the phenomenon - in this case a bank of concepts providing at least a rudimentary conceptual model of the participation process. There was a significant body of literature on skill formation practice in small firms and theory on technology adoption, but not enough to house a theory of training participation. I had some idea about how to gather the information and perhaps which questions to ask, and which incidents to attend to closely. As Miles \& Huberman (1994:17) state, "not to 'lead' with your conceptual strength can simply be self-defeating". Yet, as these authors point out, no matter how "tight" the design is bounded, focused and organised, qualitative research designs are not copyable patterns or panaceas that eliminate the need for building, revising or 'choreographing' analytic work. According to Miles \& Huberman (1994) tighter designs are a wise course providing clarity and focus for beginning researchers worried about diffuseness and overload.

To conclude this section on methodological issues, the final paragraphs describe the issues involved and procedures used to evaluate the credibility of the subsequent research findings.

\section{INTERPRETIVE CONCEPTS OF CREDIBILITY}

The traditional criteria used for evaluation of research (internal validity, external validity, and reliability) are difficult to apply to interpretive research, and are particularly problematic in case research. Consequently, different standards and criteria have been developed to apply to research outside the positivist tradition. Alternative criteria appropriate to this approach are credibility, transferability, and dependability (Hirschman, 1986). According to Lincoln and Guba (1985) these three concepts have an evaluative role in interpretive research analogous to that of the concepts of internal validity, external validity, and reliability, in positivist science.

The requirement, then, was to demonstrate that the descriptions of the different social interpretations were derived in a credible manner. A number of strategies were employed to ensure credibility. The first tactic consisted of developing a logical chain of evidence. In this study, such a chain was established firstly by having sufficient citations in the full report relating to the relevant portions of the case study data base. Secondly, the chain was established by developing a case study protocol in which all firms and all interviewees were subject to the same entry and exit procedures and interview questions, and by creating similarly organised case databases for each firm interviewed. A second tactic was to submit the interpretations to the scrutiny of the individuals upon whom they are based, and to seek their responses to its authenticity known as member checking. A third tactic was the use of comparative or collective case analysis. Multiple 
case studies enabled a higher degree of corroboration of findings to take place. The last tactic involved the researcher clarifying his assumptions, worldview, and theoretical orientation at the outset of the project, as suggested by Merriam (1988).

The second criterion, transferability, deals with the problem of knowing whether a study's findings are generalisable beyond the immediate set of cases. Interpretive studies, however, do not seek to produce results that are universally applicable. This research only attempted to generalise a particular set of results to some broader theory or research proposition. Secondly, transferability can be viewed as reader or user generalisability, where the extent to which findings can be applied to another situation is determined by the people in these situations (Merriam \& Simpson, 1995). Consequently, it is not up to the researcher to specify how findings can be applied; it is up to the consumer of the research.

The third criterion, dependability, relates to repeating the operations of the study with similar expected results. In social science, the notion of reliability is problematic because human behaviour is never static, nor is what many experience necessarily more reliable than what another person experiences (Merriam \& Simpson, 1995). In other words, there can be numerous interpretations of the same data. In interpretivist inquiry therefore, the issue is whether the researcher's judgements are dependable or consistent with the available data and free from bias and errors. In this research example, I sought dependability (reliability) through the use of three tactics. First, a case study protocol, containing each of the interview guides was used. Second, a case study database was maintained. Each of the eight cases (plus the pilot case) contained the following elements, as recommended by Miles \& Huberman (1994): (1) raw materials (including interview transcripts, researcher's field notes, other documents collected from the field); (2) partially processed text (including edited transcriptions and "commented-on" versions); (3) coded text (write-ups with specific codes attached); (4) coding scheme; (5) memos and other analytical material (researcher's reflections on the conceptual meaning of text); and (6) data displays (matrices used to display retrieved information). Third, an audit trail showed how the data were collected, how categories were derived, and how decisions were made.

In conclusion, this section has discussed methodological considerations in researching the process of participation. In particular, the nature, the utility, and the appropriateness of the case method, grounded theorising and the research design have been explained. Given the broad and complex nature of the research questions to be asked (see next section Research Procedures), the case study was chosen as it is a particularly useful open methodology for exploring an area of practice not well researched or conceptualised.

The specific procedures involved in data gathering and analysis, and the inductive process of grounded theorising for the purpose of theory building is described in detail in the following section.

\section{RESEARCH PROCEDURES}

This section describes Steps 1 to 8 and some of the procedures in detail for generating a set of propositions based on the research plan depicted previously in Figure 1. The section describes how the participants were selected, how the data was collected, and how the data was managed, analysed, and displayed.

\section{GETTING STARTED}

Three procedural issues were of great importance in starting the research: (1) the initial definition of research questions; (2) the choice regarding a priori specification of constructs; and (3) the consideration of a priori theory. Each of these issues is examined in turn.

First, the research questions provided the focus. The aim of the study was directed toward exploring and describing the decision making process of owner/managers regarding their participation with on-the-job training schemes for the first time, and to develop process theory explaining their participation. In pursuit of this aim, three interrelated research questions were initially stated:

- Q1. What issues and conditions influence the decision of small IT businesses to participate with onthe-job training?

- Q2. What are the processes small IT firms go through when participating with on-the-job training schemes for the first time?

- Q3. How can these processes be depicted in a model?

The research questions examined in the literature review provided a guiding focus to the research and permitted the specification of the kind of data to be gathered. This approach conforms with that of Strauss \& Corbin (1990:50-51) who suggest that literature from the field be used not to develop hypotheses, but to stimulate theoretical sensitivity by providing concepts and relationships that are checked out against actual data.

With respect to the second issue of using existing theoretical constructs to guide theory building, a loose conceptual model and its constructs were only used as a starting point. The conceptual model was intended to make sense of the cases, ensure that possible issues were not overlooked, provide a set of constructs to be 
investigated, and guide the author's interpretation and focus. However, as stressed by Eisenhardt (1989b), although early identification of possible constructs allows them to be explicitly studied in interviews, it is equally important to recognise that the constructs are merely tentative in the theory-building process. In this research, this was found to be true as new issues were identified during data collection that needed to be added to the analysis.

The third issue, the consideration of a priori theory is now discussed. An objective of this research was to develop a process theory of training participation. One approach to theory building research begins as close as possible to the ideal of no theory under consideration since preordained theoretical perspectives may bias and limit the findings. However, as stressed by many, it is quite impossible to achieve the ideal of a clean theoretical slate. Hence, although the research did not identify specific relationships between the constructs identified in the conceptual model, I found it helpful to make use of a meta-theory called $2^{\text {nd }}$ Generation Process Theory (Wolfe, 1994). This theory reflected my basic assumptions about the nature of the phenomena being studied (innovation, social technology), assumptions that were later supported by strong evidence in the data. The application of $2^{\text {nd }}$ Generation Process Theory was of great assistance in focussing the research efforts at the outset of the study, as it provided a frame from which the author could 'observe' the participation process and identify the key events of interest out of numerous ones that had or were occurring.

\section{SELECTING THE PARTICIPANTS}

I made two major decisions in terms of selecting the participants. First, the population of interest was specified. The population of interest were owner/managers of small firms in the IT industry who had recently decided to participate with a formal on-the-job training scheme for the first time, or those that had been approached to participate but declined. The cases were purposely selected based on the researcher's knowledge of the industry, and from discussions with industry figures.

The second critical decision was to know when to stop adding cases to the study. One approach for deciding when to stop adding cases is to conclude the field research when theoretical saturation is reached (Eisenhardt, 1989b; Strauss \& Corbin, 1990). This approach may be the ideal situation but is difficult for researchers (like doctoral students) who faced the real constraint of time schedules and funding. Hence some researchers must develop alternate approaches to answer the question of when to stop adding cases. An appropriate alternative stresses the importance of representing the variety found in the population rather than reproducing the proportions of characteristics found. This approach embodies the concepts of replication logic (Yin, 1994). As suggested by Smith (2000:78)

in research at the organisational level, the researcher includes in the sample a variety of cases operating under different conditions to ensure the theory developed is robust and provides explanations of phenomena across a number of different settings. It is the variety of conditions found under replication logic that permit the generation of theory capable of explaining the diversity of situations typically found in organisations.

Following Glaser and Strauss' (1967) technique of theoretical sampling, eight organisations were selected for their similarities as well as their differences. Because the purpose of the research was to generate theory applicable to various organisational contexts, differences were sought in organisational type such as the participatory mode - half were participants, and the other half declined participation. These differences allowed useful contrasts to be made during data analysis, which challenged and elaborated the emerging concepts.

\section{DATA COLLECTION INSTRUMENTS}

In my role as an outside observer, the semi-structured face-to-face interview was chosen as the primary data source, with observations and documents being minor sources of data. Importantly, the reliance on multiple data collection methods increased the robustness of results through triangulation.

As stressed earlier, the primary goal of the interviews was to elicit the respondent's views and experiences in his or her own terms. As such, the research used the natural setting as the direct source of data and the researcher as the key data-gathering instrument. The data gathering task was to access other people's interpretations, filter them through the researcher's own conceptual apparatus, and then feed a version of the events back to others.

Next, the primary form of data collected - critical incidents, and each of the data sources used in this study are discussed. Critical incidents are brief descriptions written by or described by individuals about significant or key events that relate to a particular topic. This technique has been used widely in organisational research. Miles \& Huberman (1994:115) cite the use of critical incidents and explained that 'sometimes a researcher wants to limit an event listing to those events seen as critical, influential, or decisive in the course of some process'. Several advantages accrued from using this method of collecting data. Respondents were asked to 
talk about specific situations, events and people. The advantage was that the interviewee could focus and reflect on the described incident posed in the interview. A collection of these responses allowed the researcher to analyse meaningful data that was grounded in the actual experiences, needs and concerns of participants.

Interviews with owner/managers dealt with the following issues: reasons or motives for adopting or rejecting the training scheme; the conditions that shaped their participation; the participation process itself; and the relationship between the small business and the off-the-job training provider. The average length of each interview was approximately $1 \frac{1}{2}$ hours for participants, and about one hour for non-participants. Interviews were not taped (a unanimous respondent request) but were transcribed by hand in all cases. Some respondents were interviewed a second time to follow-up on important issues that became evident in the data transcription, data analysis phase. The hand-written transcripts and researcher comments were typed and sent back to the interviewees for accuracy and checking within three days. When accuracy of transcription was confirmed with the respondents, the case evidence was deemed suitable for analysis. The interviews produced a detailed case study report for each firm.

\section{ANALYSIS OF DATA}

Analysing data is the heart of building theory from case studies, but it is both the most difficult and least codified part of the process. Qualitative studies tend to produce large amounts of data that are not readily amenable to mechanical manipulation, analysis, and data reduction. The problem then, was how to manage the data. The solution became the search for coherence, order and regularity. Inspired by the work of Miles and Huberman (1994) for data presentation and Strauss and Corbin (1990) for an application of grounded theory, the approach to data analysis included three steps: early steps in data analysis, within case analysis and cross case analysis.

The early steps in analysis include use of the contact summary form for reviewing the interview, the development of a computerised database for storage and easy retrieval of data, the arranging and displaying of data in tables, and the development of a coding scheme to organise the data. Within case steps involved detailed write-ups for each case assisted by the identification of critical incidents, a time line displaying stages of the participation process, the development of a logical chain of evidence, and the writing of a narrative story. Cross case analysis involved the search for cross-case patterns by combining information from several cases into a single table. From that, a new set of process oriented codes were developed, using a form of content analysis known as 'open coding' and 'axial coding' making connections between sub-categories of data into a more comprehensive set of concepts. The analytical techniques adopted during each of these three phases are explained below.

\section{EARLY STEPS IN ANALYSIS}

This section presents the analytical techniques adopted in the early stages of data analysis. Several publications give detailed instructions for organising and analysing data (Merriam, 1988; Strauss \& Corbin, 1990; Miles \& Huberman, 1994); and McIntyre (1998) for specifics on using computer databases for qualitative analysis. Miles and Huberman (1994) was drawn upon extensively for techniques to process the qualitative data. One of their techniques used in this study was to arrange empirical evidence in tables in the form of words rather than numbers. By looking at these tables, within-group similarity and across-group differences could be ascertained.

A second set of techniques were those recommended by McIntyre (1998) who highlighted data management issues, and applied database software to the interpretive analysis of qualitative data. In this research, the process of analysis was assisted by and recorded in a developing database through procedures such as entering chunks of data in fields, setting up other fields in which comments could be added, coding and sorting the interpretations; and text retrieval of selected records into the body of the research report.

A third technique, combining data collection and analysis was the use of the contact summary form. This form was useful in revising the case interview, and once transcribed, reflective remarks were recorded about the main issues identified, and initial thinking around the research questions. These remarks were ways of getting ideas down on paper and of using writing as a way to facilitate reflection and starting the analysis process. Use of the contact summary form commenced analysis by presenting an overall evaluation of the case scenario. The initial analysis was performed manually, involving writing up the contact summary sheet with some further development of the coding scheme. The transcripts from each interview were then coded and analysed for emerging themes.

The fourth technique was coding. A code is an abbreviation or symbol applied to a segment of words (e.g. sentence, paragraph). Codes served as retrieval and organising devices which allowed the rapid retrieval and clustering of all the segments related to a particular question, concept or theme. According to Miles \& Huberman (1994), coding is analysis; and coding in qualitative research involves segmenting the data into 
units, and then rearranging them into categories that facilitate insight, comparison, and the development of theory.

As suggested by Miles \& Huberman (1994:58) I created a provisional 'start list' of codes prior to fieldwork. Most of the initial coding categories were drawn from the loose conceptual model, the list of questions, and key concepts the researcher brought to the study. To be consistent with the conceptual model developed in phase 1 of the design, the preliminary descriptive coding scheme developed in this study was divided into five broad categories: environmental, organisational, individual, object and supplier. The original list was then used to codify and extract the data from the transcripts associated with the pilot case interview. As a result of this process, I found the need to add new codes. This same format was carried through the entire data collection process (across all 8 cases) and new codes were developed for emerging themes.

Immediately after the transcripts were verified by the respondents they were again read carefully and relevant portions highlighted. The highlighted portions were then keyed into the database into the field called 'excerpt' as chunks of rich text. All of the transcripts, starting with the first interview, were coded using the preliminary set of codes developed from the pilot case. Records were labeled by case along with the identifying transcript page and question number. Occasionally, a segment of the transcript resulted in the creation of a new code, or the refinement of an existing code or even the amalgamation of codes with similar meaning. The development of the coding scheme was an on-going process throughout the transcription of each of the eight cases. In fact, the formal cataloguing of "instances" into conceptual codes and categories was undertaken concurrently while the data were being collected and entered into the database. Thirty-six resulting codes within six major categories emerged from the analysis of the entire eight cases.

In addition to descriptive codes, the study identified and defined pattern or inferential codes during data analysis. Pattern codes are those that identify an emergent theme, pattern or explanation that the site suggests to the researcher; and is for qualitative researchers, an analogue to the cluster-analytic and factor-analytic devices used in statistical analysis (Miles \& Huberman, 1994). Pattern coding served two main functions in this study. First, it reduced large amounts of data into a smaller number of analytic units and, second, it helped the researcher build a cognitive map, an evolving schema for understanding what was happening in each case. Using the critical incident as a base, the participation issues and decisions were also analysed for emerging patterns and themes. Some of the issues and decisions proved to be more critical than others and some were a springboard for other decisions made at both the stage to adopt, and during the implementation stage of the training program. These issues were marked as a critical event and coded for further analysis. The emergence of the critical events adoption process (AP) theme and the detection of patterns expanded the initial coding scheme from five major categories to six.

Field notes were another important means of managing complexity in this study. As described by Van Maanen (1988), field notes are an ongoing stream of conscious commentary about what is happening in the research. By reviewing my field notes regularly (as written on the contact summary form), important issues or conflicting responses provided by different individuals were identified immediately. Second, after the interview was transcribed (and verified by the respondent as accurate), reflective remarks were directly entered into the database record within the field called 'interpretation'. Figure 2 below shows a sample data entry screen including excerpts, coding and reflective remarks. Using these remarks was my way to facilitate reflection and analytic insight. As suggested by Miles \& Huberman (1994), they are a way to convert the researcher's perceptions and thoughts into a visible form that allows reflection. In short, the reflective remarks helped me to make deeper and more general sense of what was happening, and to explain things in a conceptually different way. 
Figure 2

Sample data entry screen showing Excerpts, Codes \& Reflective Remarks

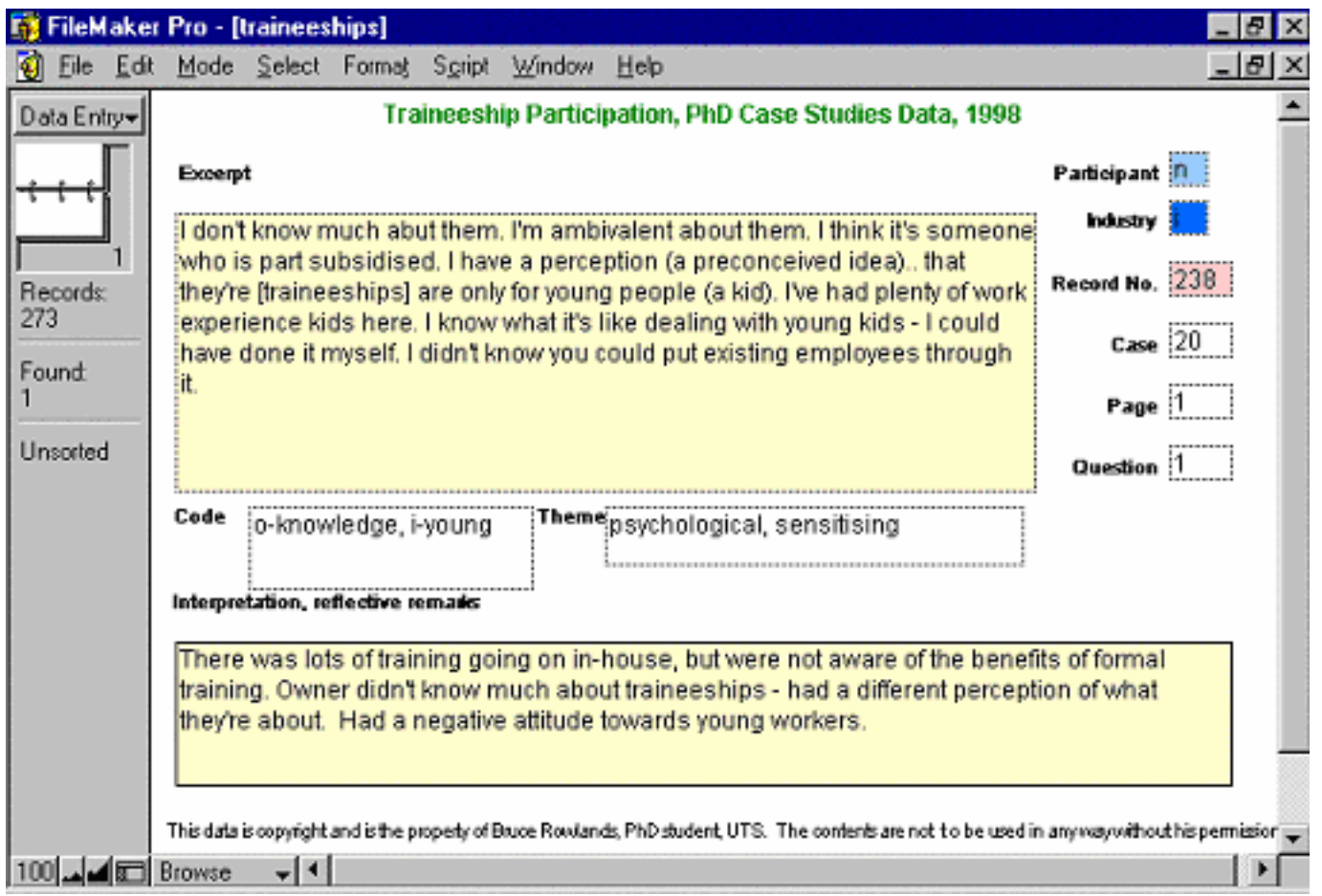

To summarise at this point, a distinguishing feature of research to build theory from case studies is the frequent overlap of data analysis with data collection. In the early phase, the afore-mentioned techniques were used separately and in combination to help the researcher identify themes, develop categories, and explore similarities and differences in the data, and relationships among them.

\section{WITHIN-CASE ANALYSIS}

The second phase, Within-Case-Analysis, typically and necessarily involved detailed write-ups for each case. These writings were often simply pure descriptions, but were central to the generation of insight because they helped me cope early in the analysis process with the enormous volume of data. However, there is no standard format for such analysis. The procedures followed to analyse each case are summarised in Table 1.

Table 1

Within-Case Analysis Procedures

Step 1: Development of a File Maker Pro Database
1.1 Codify and extract data from the transcripts using the validated coding scheme
1.2 Group extracted segments under categories (codes and pattern codes)
1.3 Read and add reflective remarks and observational notes to database records
Step 2: Displaying Data: developing summary tables
2.1 Factors cited for participation/non participation in on-the-job training were
displayed in tables.
2.2 Critical incidents and a time line describing stages of the participation process were
displayed in a table.
Step 3: Development of a Logical Chain of Evidence
3.1 Identify set of distinct evaluative elements
3.2 Identify initiating opportunities from in-depth analysis of case accounts
3.3 Establish the logical chain of evidence between the participation / non- participation
process and the conditions above
3.4 Provide a decision 'story' that explains the extent to which each challenge was
overcome


As a first step the researcher developed a set of computer records in a database for each participation and rejection case. The database organised and documented the data collected for each case. The eight case files generated records containing the following elements: excerpt, codes, themes, interpretations as reflective remarks and other identifying fields such as case number, research question, industry etc. A sample data entry and retrieval screen from the database is shown in Figure 2.

The second step employed some of the displays proposed by Miles \& Huberman (1994:91) as one approach to managing the problem of huge volumes of data. These authors define a display as a "visual format that presents information systematically, so the user can draw valid conclusions and take needed action". The within-case displays adopted in this research include the critical incident chart, and the time ordered matrix. Displays such as these made ideas visible and permanent. They also served two other key functions: data reduction, and presentation of analysis that allowed it to be grasped as a whole.

In order to streamline the data analysis process and still obtain relevant information, a table highlighting critical incidents and a timeline were developed. The objective was to describe the factors and issues that influenced the decision process, and secondly to describe the critical events that took place during the decision process to preserve chronology and illuminate the processes occurring. Critical incidents provided a focused way to examine the decision making process. The critical incident time line was developed for each participating case and chronologically arranged as a series of decisions made by owner/managers during the participation process.

These critical incidents enabled the researcher to focus on the stages of the decision making process. The participants were asked to identify and describe the decisions and sequence of events that were made about the traineeship program during the time before participation. To help the participant reflect upon this stage, prompts of 'early', 'middle', 'late' and 'now' were added to the time line. The idea to add these prompts came after the pilot study was conducted to help the participants recall the information more clearly and provide as much detail as possible about the decisions made during this stage. It also helped myself to construct the chronological flow of information. Miles \& Huberman (1994:115) advocate the use of a time line to supplement the critical incidents and provide a basis to "... examine and compare events that occurred during a given time period".

In order to complete the third step of within-case analysis, to understand the 'how' and the 'why' associated with each case and hence to provide answers to the research questions, a logical chain of evidence (Yin, 1994) was established. This chain of evidence involving participation reasons and contextual conditions was built in sequence. Step 3.1 involves identifying and then describing a set of distinct evaluative elements for each case. Each element is described in turn.

The first element - Background required details of the IT industry and general economic conditions. Facilitating Conditions required a description of favourable contextual condition(s) which enhanced or strengthened the participation/ rejection factors and hence increased the chances of the participation process. Opportunity meant a favourable event, which, if seized, could help fulfil an envisioned goal. Challenge implied an envisioned goal or unexpected endeavour whose fulfilment pushed the process closer to success. Tactic implied an event representing an action or decision or a series of actions and decisions aimed at preparing the small business for the training scheme and introducing it in such a way as to ensure its success. Unexpected event describes an event, which affected the anticipated progress of the training scheme. Unfavourable condition included contextual condition(s) which impeded or hindered the participation process. Compensatory mechanism refers to a contextual condition compensating for a strategy violating one of the accepted beliefs concerning 'known factors' impacting on technology adoption. Outcome, the end result of the process.

The second sub-step (3.2) identifies the initiating opportunities encountered during the participation process. These were identified through an in-depth analysis of the interviewee's accounts, and the context or background surrounding each case. Because this was the first time an on-the-job training scheme had been adopted in each firm, the challenge in each case was to describe the tactics adopted to cope with the encountered problems, anticipated or not, and the facilitating and unfavorable conditions. Each of the elements in this chain were identified through accounts in the transcripts (having previously been coded and entered in the database).

Sub-step 3.3, involved documenting the chain of evidence by having sufficient citations in the report linked to the relevant portions of the case study database, and the initial research questions. In other words, clear crossreferencing to methodological procedures and to the resulting evidence.

Fourth, sub-step 3.4 entails combining the qualitative responses into narratives or decision 'stories'. These 'stories' overview and correlate the chain of evidence. Throughout the story, various displays are used to summarise the participation issues cited by the owner/managers. Decisions made during the participation process are explained and displayed in chronological order in a time line. In the time lines, the chart indicates the temporal order of events, choices and activities and has been decomposed into periods ('early', 'middle', 
'late', and 'now'). However, these time-line periods should not be viewed to be synonymous with any of the phases found in the decision-making literature - they were merely a descriptive organising device for rendering a complex sequence of events more comprehensible. However, the periods do have conceptual significance in the resulting model, which is explained further in Rowlands (2001), in that the activities involved in the early phase were concerned with forming a favourable commitment to on-the-job training. Furthermore, the middle and later phases were more concerned with financial and operational detail respectively.

\section{CROSS-CASE ANALYSIS}

The last analytic strategy, cross-case analysis (involving phase 3 of the design) is now described.

First, the theory building process commenced with the development and presentation of an initial conceptual model based on evidence from the literature, the coding scheme resulting from the pilot case, and the theoretical assumptions associated with $2^{\text {nd }}$ Generation Process Theory. The conceptual model then became a vehicle for generalising to the other eight cases. Second, the design of the research lent itself to cross-case analysis of data and the search for patterns. Replication logic (which formed a basis for the selection of the cases) became the key to the rigorous analysis of the cross case data. Rowlands (2001) documents cross-case analysis of the four participating firms and made comparisons with the four non-participating firms. A number of analytic techniques suggested by Miles \& Huberman (1994) were used to cross-analyse the data.

The most basic way of cross-analysing the data from several cases is with the unordered descriptive metamatrix. This device assembles data from several cases in an efficient, manageable format providing 'inclusion' of all the relevant information. Secondly, the table tabulates the frequency of events and as such draws rapid attention to the dominant issues, keeping the researcher analytically honest while protecting against bias. Table 2 below provides an example descriptive meta-matrix that was used extensively in the research. The use of the unordered descriptive meta-matrix establishes a grounding of the data. 
Table 2

Example Unordered Descriptive Meta-matrix: Participants citing Organisational Factors as relevant to

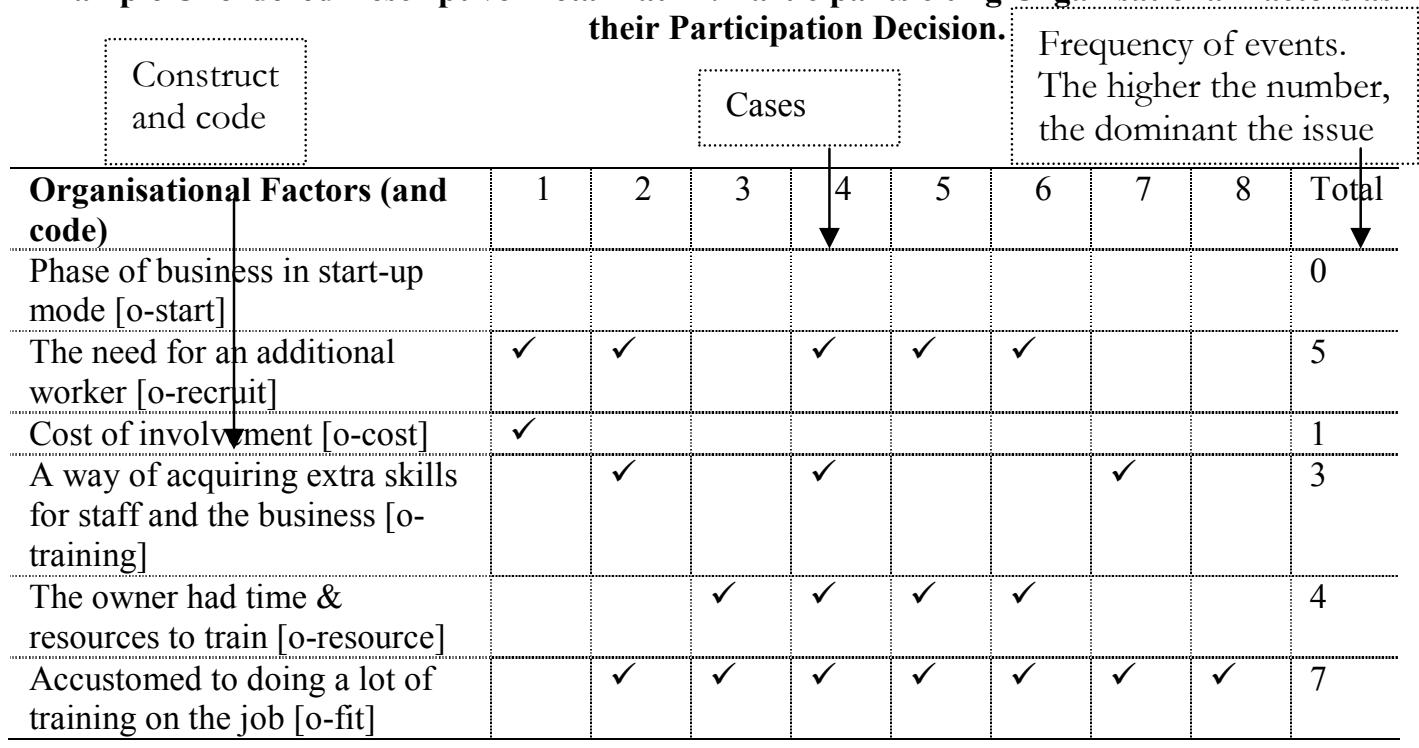

At the conclusion of working through each of the cases as described above in meta-matrix format, the analysis then focused on developing process codes wholly grounded in the research data involving cross-case comparisons. While the excerpts in the transcripts had been coded according to the codes described earlier, a new set of process-oriented codes were derived and entered in a File Maker Pro field called Theme. The triggers which initialised the dynamic scanning of transcripts for significant data items were the critical incidents from the interview questions, the time-lines and logical chains of evidence developed for each case. The temporal sequence of classifying the data became a key organising structure in this process, and using the notions of "early", "middle" and "late", the analysis process started a formal full-scale cataloguing of dataitems under various higher-level conceptual categories. This intensive back and forth analysis of the entire set of database excerpts, along with a continually growing body of results, finally results in producing eight major process categories (c.f. Table 3 ).

Table 3

Descriptive Titles for the Process Categories Identified

\begin{tabular}{l} 
Category \\
Information \\
Psych-Inhibitor \\
Sensitisor \\
Impetus \\
Diagnostic-cost \\
Feasibility \\
Facilitator \\
Interrupter \\
\hline
\end{tabular}

\section{Descriptive Title}

Information on on-the-job training schemes from various sources.

Internal or external events inhibiting interest in on-the-job training schemes.

A positive attitude towards young people in general and a willingness to train on the job.

Internal or external events precipitating serious consideration of on-the-job training schemes.

Defining and confirming costs and benefits.

Consideration of feasibility and impact of new apprentices on the firm.

Positive influence to facilitate training provider and trainee choice.

Interrupter

Negative forces that slowed operational choices.

A distinguishing characteristic to be observed through this cross-case analysis process was that, as more and more database transcripts became part of the analysis, fewer and fewer new categories emerged, and the existing ones become "saturated". Thus, instead of the collection, coding and counting of activities, which dominated activity in the early steps and within-case analysis, the analytical aspects of the research process became more intense. Moreover, in this later integrative stage of analysis the focus of the constant comparison moved up, from the level of the data item, to the level of the conceptual categories themselves. Patternmatching aspects of this category-level analysis proved to be instrumental in recognition of the broader "themes" in the results.

The procedure used by myself was a form of content analysis where the data were read and categorised into concepts that were suggested by the data and guided by initial temporal constructs. This technique is known as 'open coding' (Strauss \& Corbin, 1990) and it relies on an analytic technique of identifying possible categories and their properties and their dimensions. Once all the data were collected and coded, the concepts were organised by recurring theme. These themes became prime candidates for a set of stable and common 
categories, which linked a number of associated concepts. This is known as 'axial coding' (Strauss \& Corbin, 1990) and relies on a synthetic technique of making connections between sub-categories to construct a more comprehensive scheme. The eight cases were then re-examined and re-coded using this proposed scheme, the goal being to determine that set of categories and concepts that covered as much of the data as possible. This iterative examination yielded a set of broad categories and associated concepts that described the salient conditions, events, experiences, and consequences associated with the participation process.

The iteration between data and concepts ended when enough categories and associated concepts had been defined to explain what had been told across all sites, and no additional data were being collected to add to the set of concepts or categories, a situation Glaser \& Strauss (1967) refer to as 'theoretical saturation'. The resultant framework is empirically valid as it can account of the unique data of each site, as well as generalise patterns across the sites. That is, the categories describe the data, and they also interpret the data. This interpretation lead into the next step of analysis (step 6), involving making inferences and formulating propositions. Space limitations of the paper preclude a detailed description of step 7 (enfolding the literature) and step 8 (reaching closure). However, both steps involved discussing the propositions with the extant literature. They did so by returning to the literature to note consistencies with and departures from findings of earlier research. This involved asking what it is similar to, what does it contradict, and why? In pursuit of this objective, for each proposition, the research indicated the extent to which it was supported by previous research and the extent to which the research has added some new perspective or idea when thinking about the process of training participation.

To re-cap on the data analysis procedures, I found presenting information systematically in a visual format to be very helpful in conducting the analysis. To illustrate this, the primary methods of data analysis and presentation were through the use of matrices, a logical chain of evidence involving a critical incident time line, a software database to systematically conduct textual analysis, and the presentation of a "story" piecing together interviewee accounts taken from the case study database. The data were then analysed using withincase and cross-case matrix construction. Unstructured computer software was used to systematically conduct textual analyses producing accounts based on instantiation through quotations of text. The chain of evidence, the time-lines, and database structure constituted an intermediate level of theorising between the accounts the interviewees gave and a more abstract and general process model. The thematic analysis embedded in the database structure thus became both an expression of my emerging ideas about the participation process in general, and a useful tool in comparing the eight cases in a systematic fashion. For further procedural descriptions of how the grounded theory was developed and the propositions generated, the reader is referred to Rowlands (2001)

\section{DISCUSSION, IMPLICATIONS \& CONCLUSIONS}

Given that this is a paper about conducting interpretive research, it is appropriate to focus the discussion on the particular research approach taken. The research process faced a number of conceptual and methodological problems when developing process knowledge in this field of study.

The first problem involved perspective. The findings of the literature review suggested that differences in intentions, processes, and contexts around participation with training initiatives have been largely overlooked by research that tends to focus on inputs or outputs but not process. The approach taken in this research was different from existing frameworks on training participation research, which tend to share three characteristics. Firstly, these models are deterministic and assume that objective factors outside human intention are responsible for adoption. Secondly, they are variance models and hence do not adequately capture the contextual and processual issues that are fundamental to examining organisational change. Thirdly, they focus primarily on factors of economic cost and benefit, and hence do not examine, over time, the dynamics and interplay of social influences, business context, and individual owner/manager action.

In this particular example, it was made clear that a socio-technical and organisational innovative perspective approaching participation as a multi-dimensional construct locally defined by the owner/managers taking into account social issues represents a more realistic approach than more common attempts to find objective criteria such as training expenditure or economic benefits. In short, this research studied the process of participation from the viewpoint of the owner/manager and how they defined their situation locally.

The second problem concerns the contribution of 'process' research as opposed to 'variance' models to the understanding of organisational phenomena. Clearly, process studies address questions that are unanswerable by variance research: for example, What are the typical events followed as a small firm moves from limited knowledge of a training initiative to willingness to participate in a trial? As Van de Ven \& Huber (1990:213) state, 'process studies are fundamental to gaining an appreciation of dynamic organisational life'. However, it can be argued that because the 'process' approach usually only allows the consideration of small samples of organisations, it is difficult to draw generalisable conclusions. 
Third, it is important to consider the overall demand of this methodological approach on the researcher. For instance, interpretive research usually results in the collection of large amounts of data almost surpassing human ability to compile without the aid of specialist software for textual storage and retrieval. B

Fourth, because of the demands and problems encountered during qualitative research, researchers must have a great interest in and dedication to the object of the research. While it is essential to gain the trust and confidence of owner/managers future researchers should not underestimate the time and effort required to conduct these kinds of studies, nor the difficulty in gaining access to busy and sometimes sceptical managers for lengthy and detailed interviews.

Another related problem to be overcome from this research approach concerns the logistics in carrying out indepth case research. It was learned that one must be willing to meet with the informants a number of times (always at a time that suited them) in order to establish rapport before informants were ready and willing to be interviewed. Despite these constraints, in-depth case studies remain, this paper suggests, the best approach available to collecting rich data. The reward clearly appears to be a deeper and broader understanding of small business decision-making and the ability to contribute significantly to cumulative knowledge in the field.

Fifth, the discussion now turns to the design and procedures I used for conducting the inductive process so central to interpretive research. I have already drawn attention to the fact that phase 1 of the design (c.f. Figure 1) was quasi deductive, so the question remains, does this compromise the claim that the research approach was genuinely interpretive? To address this question, I will re-state my reasons for the a priori use of literature, and then evaluate the research procedures based on a set of principles suggested by Klein \& Myers' (1999) for conducting interpretive research.

In terms of the design, I chose to be initially guided by the literature, yet the bulk of the reflection with the literature came after the substantive propositions were generated in phase 3 of the design. Nevertheless, the preliminary literature review provided a guiding focus to the research and stimulated theoretical sensitivity by providing concepts and relationships that were checked out against actual data. However, in my defence, the overall design and case method allowed the research to flow in the more common direction from data to theory - the process of inducting theory.

Secondly, by referring to the principles suggested by Klein \& Myers (1999), I can defend the research as being interpretive by reference to our definition and four key principles. When applying Klein \& Myers (1999) definition of interpretive research (as discussed in the paper's Introduction), the research is interpretive given that there was no use of formal propositions, quantifiable measures of variables, or drawing inferences from a representative sample to a population. Nor were any dependent or independent variables defined. The research approach instead was intent on understanding the phenomena through the meanings that the owner/managers assigned to them. This was achieved by the use of unstructured interviews for data collection and grounded theory techniques for data analysis. The GT techniques of open and axial coding are well suited to the supporting Klein \& Myers' fundamental first principle for conducting interpretive field research, that of the hermeneutic circle. This principle suggests that all human understanding is achieved by iterating between considering the interdependent meaning of the parts (open codes) and the whole that they form (axial codes).

Klein \& Myers' (1999) second principle of contextualisation requires critical reflection of the social and historical background. In this example, I documented the context of the study and demonstrated how important it was to understand how policy has evolved in terms of the emphasis successive governments have placed on promoting employment and training initiatives within small firms. The fourth principle abstraction and generalisation, was attained through my continuation of the analytic generalisation process by combining the findings with the innovation and organisational decision-making literature. In step 6, the research developed a set of theoretical propositions that defined and explained the participation process. The research then discussed the propositions by returning to the literature in step 7 to note consistencies with and departures from findings of earlier research. The sixth principle - multiple interpretations, was achieved by a research design based on replication logic and the deliberate intention of comparing and contrasting differences in interpretations by the participants and non-participants as expressed in their narratives and critical incidents.

To conclude, the research recognised the serious lack of established theory and prior empirical research on training within the IT industry in general. Therefore, at this stage of knowledge accrual about training participation, the need for greater precision in research was viewed in balance with the long-term benefits of first generating meaningful, and field-relevant theory. In this sense, the research circumstances of this investigation were clearly favourable for using an inductive, interpretive and grounded theory approach. 


\section{REFERENCES}

Berger \& Luckmann (1967), The Social Construction of Reality: A Treatise in the Sociology of Knowledge, Doubleday, New York.

Bijker, W., Hughes, P., \& Pinch, T., (1987), The Social Construction of Technological Systems: New Directions in the Sociology and History of Technology, MIT Press, Cambridge Mass.

Burrell, G., \& Morgan, G., (1979), Sociological Paradigms and Organisational Analysis, London, Heinmann.

Cavaye, A., (1996), Case Study Research: A Multi-faceted Research Approach for IS, Information Systems Journal, Vol 6, pp 227-242.

Chetty, S., (1996), The Case Study Method for Research in Small and Medium Sized Firms, International Small Business Journal, Vol 15, No 1, pp. 73-85.

Eisenhardt, K., (1989a), Making Fast Strategic Decisions in High Velocity Environments, Academy of Management Journal, Vol 32, No 3, pp. 543-576.

Eisenhardt, K., (1989b), Building Theories from Case Study Research, Academy of Management Review, Vol 14, No 4, pp. 532-550.

Galal G (2001) From Context to Constructs: the use of grounded theory in operationalising contingent process models. European Journal of Information Systems 10, 2-14.

Glaser, B., \& Strauss, A., (1967), The Discovery of Grounded Theory: Strategies for Qualitative Research, Aldine, Chicago.

Hayton, G., McIntyre, J., McDonald, R., Sweet, R., Noble, C., Smith A., \& Roberts P., (1996), Final Report: Enterprise Training in Australia, Office of Training and Further Education, Melbourne.

Hirschman, E., (1986), Humanistic Inquiry in Marketing Research: Philosophy, Method and Criteria, Journal of Marketing Research, 23, pp. 237-249.

Jones S \& Hughes J (2001) Understanding IS Evaluation as a complex social process: a case study of a UK local authority. European Journal of Information Systems 10, 189-203.

Klein, H., \& Myers, M., (1999), A Set of Principals for Conducting and Evaluating Interpretive Field Studies in Information Systems, MIS Quarterly, Vol 23, No 1, pp 67-94.

Klein, H., \& Myers, M., (2001), A Classification Scheme for Interpretive Research in Information Systems, chapter 9 from Trauth (2001), 218-239.

Langley, A., \& Truax, J., (1994), A Process Study of New Technology Adoption in Smaller Manufacturing Firms, Journal of Management Studies, Vol 31, No 5, pp 593-651.

Lee, A., (1991), Integrating Positivist and Interpretive approaches to Organisational Science, Organisational Science, Vol 2, No 4, pp, 342-365.

Lincoln, Y., \& Guba, E., (1985), Naturalistic Inquiry, Sage, Newbury Park, California..

Markus, M. L., (1994), Electronic Mail as the Medium of Managerial Choice, Organisation Science, Vol 5, No 4, pp 502-527.

McIntyre, J., (1998), Using Databases for Qualitative Analysis, Chapter 8 in Higgs. J., Writing Qualitative Research, CPEA, Hampden Press, pp 81-92.

Merriam, S., (1988), Case Study Research in Education: A Qualitative Approach, Jossey-Bass, San Francisco.

Merriam, S., \& Simpson, E., (1995), A Guide to Research for Educators and Trainers of Adults, $2^{\text {nd }} \mathrm{Ed}$, Kreiger Publishing, Florida.

Miles, M., \& Huberman, A., (1994), Qualitative Data Analysis: An Expanded Sourcebook, Sage, Thousand Oaks..

Mohr, L., (1982), Explaining Organisational Behaviour, Jossey-Bass, San Francisco.

Orlikowsi, W., \& Baroudi, J., (1991), Studying Information Technology in Organisations: Research Approaches and Assumptions, Information Systems Research, Vol. 2, No. 1, pp. 1-28.

Rogers, E.M., (1995), Diffusion of Innovations (4th ed), Free Press, New York.

Rowlands, B., (2001), An Interpretive Study of Training Initiative Participation among Small Firms in the IT industry, Australian Conference on Information Systems, Southern Cross University, pp. 547-556.

Saunders, S., (2001), Issues and Directions from a Review of the Australian Apprenticeship and Traineeship Literature, NCVER, http:/www.ncver.edu.au/research/proj/nr9012i.pdf [accessed: May 2001]. 
Smith, A., Roberts, P., Noble, C., Hayton, G., \& Thorne, E., (1995), Enterprise Training: The Factors that Effect Demand, Vol 1, OTFE, Melbourne.

Smith, A., (2000), Casing the Joint: Case Study Methodology in VET Research at the Organisational Level, ANZ Journal of Vocational Education Research, Vol 8, No 1, pp. 73-91.

Strauss, A., \& Corbin, J., (1990), Basics of Qualitative Research: Grounded Theory Procedures and Techniques, Sage, Newbury Park, California.

Trauth, E. M., (2001), Qualitative Research in IS: Issues and Trends, Idea Publishing.

Urquhart, C., (1997), Exploring Analyst-Client Interaction Communication: Using Grounded Theory techniques to Investigate Interaction in Informal Requirements Gathering, in Information Systems and Qualitative Research, Lee, A., Liebenau, J., \& DeGross, J., (eds), Chapman \& Hall, London.

Urquhart, C., (2001), An Encounter with Grounded Theory: Tackling the Practical and Philosophical Issues, chapter 5 from Trauth (2001), pp 105-139.

Van de Ven, A., \& Huber, G., (1990), Longitudinal Field Research Methods for Studying Processes of Organisational Change, Organisational Science, Vol 1, pp 213-219.

Van Maanen, J., (1979), The Fact of Fiction in Organisational Ethnography, Administrative Science Quarterly, Vol 24, No 2, pp. 539-550.

Walsham, G., (1995), Interpretive Case Studies in IS Research: Nature and Method, European Journal of Information Systems, Vol 4. No 2, pp.74-81.

Whetten, D., (1989), What Contributes a Theoretical Contribution?, Academy of Management Review, Vol 14, No 4, pp 490-495.

Wolfe, R., (1994), Organisational Innovation: Review, Critique and Suggested Research Directions, Journal of Management Studies, Vol 31, No 3, pp 405-431.

Yin, R., (1994) Case Study Research: Design and Methods, $2^{\text {nd }}$ ed, Sage, Beverly Hills, California. 